Acta Protozool. (2019) 58: 191-200

\title{
Morphology and Morphogenesis of a Chinese Population of the Soil Urostylid Ciliate, Extraholosticha sylvatica (Foissner, 1982) Li et al., 2017 (Ciliophora, Hypotrichia)
}

\author{
urn:Isid:zoobank.org:pub:AB15AF41-E890-44D8-B197-F01EDFE1CEBC
}

\author{
Jingbao LI ${ }^{\mathrm{a}}$, Keqing WEN", Erkang ZHU ${ }^{\mathrm{b}}$, Jingyi WANG ${ }^{\mathrm{b}}$ \\ ${ }^{\text {a }}$ Key Laboratory for Space Bioscience and Biotechnology, Institute of Special Environmental Biophysics, School of Life Sciences, \\ Northwestern Polytechnical University, Xi'an, China \\ ${ }^{b}$ Laboratory of Protozoological Biodiversity and Evolution in Wetland, College of Life Sciences, Shaanxi Normal University, Xi'an, \\ China
}

\begin{abstract}
A soil urostylid ciliate Extraholosticha sylvatica, isolated from southern China, is studied using live observation and protargol impregnation. The main ontogenetic features of E. sylvatica are as follows: (a) in the proter, only the posterior part of the parental adoral zone of membranelles is renewed, while the anterior portion is retained; undulating membranes anlage undergo, like most hypotrichs, depolymerization of old undulating membranes and differentiation of new structures; (b) the oral primordium in the opisthe and the frontoventraltransverse cirral anlagen in both daughter cells are formed with contribution of the parental midventral cirri; (c) three frontal, one buccal, three to five frontoventral, one or two frontoterminal, two or three pretransverse ventral and six to 11 transverse cirri and 16-22 midventral pairs are generated from frontoventral-transverse cirral anlagen; (d) in both the left and the right marginal rows as well as the dorsal kineties, each two anlagen are formed intrakinetally; three to six caudal cirri are formed at the posterior end of the 5th dorsal kinety anlage; (e) the macronuclear nodules fuse into a single mass during the process.
\end{abstract}

Keywords: Extraholosticha, morphogenesis, soil ciliate, Urostylida.

\section{INTRODUCTION}

Ciliates of the subclass Hypotrichia Stein, 1859 have a huge diversity with over 1000 nominal species reported and exhibit extremely diverse morphological

Address for correspondence: Laboratory of Protozoological Biodiversity and Evolution in Wetland, College of Life Sciences, Shaanxi Normal University, Xi'an 710119, China; E-mail address: Wangjingyi629@163.com and morphogenetic features (e.g. Berger 1999, 2006, 2008, 2011; Kaur et al. 2019; Kumar et al. 2018; Luo et al. 2018, 2019; Méndez-Sánchez et al. 2018; Shao et al. 2019). Urostylids, mainly characterized by a dorsal ciliature composed of bipolar kineties only and a prominent midventral complex, are one of the largest groups of hypotrichia. Up to now, more than 200 species have been described in this group (e.g., Chen et al. 2018; Jung et al. 2018; Jung and Berger 2019; Lyu et al. 2018a, b; Moon et al. 2019; Sheng et al. 2018; Song and Shao 2017; Zhang et al. 2019; Zhu et al. 2019). 
According to Berger (2006), Holostichidae is a species-rich group in Urostyloidea. Caudiholosticha was founded by Berger (2003), with C. stueberi as the type species, the number of species in the genus Caudiholosticha was up to 17 previously (Berger 2003, 2006; Foissner 2016). Recently, Li et al. (2017) found dorsal marginal kineties present in C. stueberi and designated Caudiholosticha as a monotypic subgenus of Uroleptus, as well as assigned all 16 other Caudiholosticha species to six newly established urostylid genera.

Caudiholosticha sylvatica (basionym Holosticha sylvatica) was transferred to Extraholosticha as the type species by Li et al. (2017) since Extraholosticha sylvatica has two interesting features, namely, some cirri behind the left frontal cirrus are present and all the caudal cirri are posterior to the rightmost dorsal kinety.

During a survey of ciliates in Peninsula Lake Park of Wanning, Hainan, China in August 2018, Extraholosticha sylvatica was collected from marsh soil. This, for the first time, gives us an opportunity to reveal some details of the morphogenesis of this genus.

\section{MATERIALS AND METHODS}

\section{Sampling and cultivation}

The present species was isolated from a soil sample with humus (about $50 \mathrm{~g}$ ) collected from the surface $(0-10 \mathrm{~cm})$ in Peninsula Lake Park of Wanning, Hainan Province, China (18 $40^{\circ} 48^{\prime}$ N, $110^{\circ} 21^{\prime} 44$ 'E) on 24 August 2018. The non-flooded Petri dish method was used to stimulate ciliates to excyst (Foissner 2014). Isolated specimens were cultured in Petri dishes at room temperature (about $25^{\circ} \mathrm{C}$ ) in the laboratory using mineral water (Nongfu Spring) with squeezed rice grains to enrich the availability of bacterial food.

\section{Morphology and morphogenesis}

Specimens were examined both in vivo using bright field and DIC microscopy, and photographed using a digital camera (differential interference contrast microscopy, Olympus BX51). Ciliary pattern and nuclear apparatus were revealed using protargol staining method of Wilbert (1975). Protargol was synthesized according to Pan et al. (2013). Counts and measurements of stained specimens were performed with an ocular micrometer at a magnification of $1000 \times$. Drawings were made with the help of a drawing device. To illustrate the changes that occurred during morphogenesis and reorganization, the old (parental) ciliary structures are depicted by contour, whereas new ones are shaded black. For an explanation of general terminology, see Berger (2006).

\section{Voucher material}

Protargol slides have been deposited in the Laboratory of Protozoological Biodiversity and Evolution in Wetland, Shaanxi Normal University, China (accession numbers: ZEK2018082405A-G).

\section{RESULTS}

\section{Morphology of the Chinese population (Fig. 1; Table 1)}

The living morphology and infraciliature of the present population of Extraholosticha sylvatica closely resemble previous descriptions (Berger and Foissner 1989, Borror and Wicklow 1983, Foissner 1982, Kumar et al. 2010, Shin and Kim 1993).

Cells $120-210 \mu \mathrm{m} \times 40-80 \mu \mathrm{m}$ in vivo $(\mathrm{n}=6)$ and 105-194 $\mu \mathrm{m} \times 45-110 \mu \mathrm{m}$ after protargol preparation. Specimens distinctly widened due to the preparation procedures. Oval to elliptical in outline, with both ends broadly rounded, flexible but not contractile. Cortical granules colorless, about $0.5 \mu \mathrm{m}$ in diameter, arranged in short longitudinal rows on dorsal and ventral surfaces (Fig. 1F). Contractile vacuole with two longitudinal collecting canals and located at about mid body near left margin, $15 \mu \mathrm{m}$ in diameter when fully extended. Food vacuoles $10-25 \mu \mathrm{m}$ in diameter and lots of colorless crystals located at the rear body (Fig. 1D, E). Cytoplasm transparent, usually with many lipid droplets (1-5 $\mu \mathrm{m}$ across) (Fig. 1G). 52-96 macronuclear nodules scattered throughout body and two to nine micronuclei (Fig. 1C, H, I).

Adoral zone extending to about $40 \%$ of cell length and consisting of 40-56 membranelles with its distal end extending moderately onto ventral side, with DEvalue ca. $0.22(\mathrm{n}=16)$. One buccal, two frontoterminal and three frontal cirri; three to five frontoventral cirri behind the leftmost frontal cirrus; cirrus III/2 located closely behind the rightmost frontal cirrus; midventral complex consisting of 16-22 pairs and extending to about $2 / 3$ of body length; usually two pretransverse cirri (20 of 21 specimens analyzed; Table 1$)$ and six to 11 transverse cirri; right marginal row commences near the lower frontoterminal cirrus and ends subterminally, left marginal row begins left of proximal portion of adoral zone of membranelles and ends caudally.

Five dorsal kineties more or less bipolar, composed of 23-40, 24-38, 19-30, 20-31 and 22-38 dikinetids, respectively, cilia of which about $3 \mu \mathrm{m}$ in length. Three to six caudal cirri at the posterior end of the rightmost dorsal kinety (Fig. 1A, B). 
Table 1. Morphometric characterization of the Chinese population of Extraholosticha sylvatica.

\begin{tabular}{|c|c|c|c|c|c|c|c|}
\hline Character $^{\mathrm{a}}$ & Mean & Min & Max & $\mathrm{M}$ & $\mathrm{SD}$ & $\mathrm{CV}$ & $\mathrm{n}$ \\
\hline Body, length & 148.8 & 105 & 194 & 147 & 20.8 & 14.0 & 19 \\
\hline Body, width & 75.1 & 45 & 110 & 76 & 16.1 & 21.4 & 19 \\
\hline Body length: width & 2.0 & 1.5 & 2.6 & 2.0 & 0.3 & 16.6 & 18 \\
\hline Adoral zone, length & 57.1 & 45 & 68 & 59 & 7.4 & 12.9 & 19 \\
\hline Adoral membranelles, no. & 47.6 & 40 & 56 & 47 & 4.5 & 9.5 & 19 \\
\hline Adoral zone length: body length & 0.4 & 0.3 & 0.5 & 0.4 & 0 & 11.8 & 18 \\
\hline Frontal cirri, no. & 3.0 & 3 & 3 & 3 & 0 & 0 & 19 \\
\hline Frontoventral cirri, no. & 3.8 & 3 & 5 & 4 & 0.7 & 18.2 & 21 \\
\hline Buccal cirri, no. & 1.0 & 1 & 1 & 1 & 0 & 0 & 19 \\
\hline Frontoterminal cirri, no. & 1.9 & 1 & 2 & 2 & 0.2 & 11.5 & 19 \\
\hline Midventral pairs, no. & 18.4 & 16 & 22 & 18 & 1.6 & 8.9 & 19 \\
\hline Right marginal cirri, no. & 43.8 & 27 & 52 & 45 & 6.5 & 14.8 & 19 \\
\hline Left marginal cirri, no. & 41.0 & 30 & 52 & 41 & 5.2 & 12.6 & 19 \\
\hline Pretransverse cirri, no. & 2.0 & 2 & 3 & 2 & 0.2 & 10.4 & 21 \\
\hline Transverse cirri, no. & 9.2 & 6 & 11 & 9 & 1.3 & 14.4 & 21 \\
\hline Caudal cirri, no. & 4.2 & 3 & 6 & 4 & 0.9 & 22.4 & 19 \\
\hline Dorsal kineties, no. & 5.0 & 5 & 5 & 5 & 0 & 0 & 19 \\
\hline Dorsal kinety 1, bristles, no. & 32.8 & 23 & 40 & 33 & 4.3 & 13.0 & 17 \\
\hline Dorsal kinety 2 , bristles, no. & 29.7 & 24 & 39 & 29 & 4.5 & 15.2 & 19 \\
\hline Dorsal kinety 3, bristles, no. & 23.2 & 19 & 30 & 22 & 3.1 & 13.5 & 18 \\
\hline Dorsal kinety 4, bristles, no. & 24.7 & 20 & 31 & 24 & 2.9 & 11.9 & 18 \\
\hline Dorsal kinety 5 , bristles, no. & 27.4 & 22 & 38 & 26 & 4.5 & 16.5 & 18 \\
\hline Total number of bristles & 138.5 & 123 & 158 & 137 & 9.5 & 6.9 & 17 \\
\hline Macronuclear nodules, no. & 67.6 & 52 & 96 & 68 & 8.9 & 13.1 & 16 \\
\hline Macronuclear nodules, length & 9.1 & 4 & 14 & 9 & 3.0 & 33.4 & 16 \\
\hline Macronuclear nodules, width & 5.0 & 3 & 8 & 4.5 & 1.5 & 30.2 & 16 \\
\hline Micronuclei, no. & 4.4 & 2 & 9 & 4 & 2.2 & 50.4 & 16 \\
\hline
\end{tabular}

${ }^{a}$ All data is based on protargol-stained specimens with measurements in $\mu \mathrm{m}$. Abbreviations: $\mathrm{CV}=$ coefficient of variation in $\%$; $\mathrm{M}=$ median; Max $=$ maximum; Mean = arithmetic mean; Min = minimum; $\mathrm{n}=$ sample size; no. = number; $\mathrm{SD}=$ standard deviation.

Morphogenesis during binary fission in Extraholosticha sylvatica (Figs 2-4)

Oral apparatus, and frontal, midventral and transverse cirri

In the early stage, the oral primordium of the opisthe, composed of tightly arranged basal bodies, appears to the left of the midventral pairs and below the buccal vertex (Figs 2A, 4A). Later, several posterior midventral pairs at about mid body disaggregate and join in the construction of the oral primordium of the opisthe. The oral primordium of the opisthe begins to differentiate into membranelles (Fig. 2B, C). Meanwhile, the fron- toventral-transverse cirral anlagen (FVT-anlagen) in both daughter cells originate with contribution of some parental midventral pairs (Figs 2C, 4B), the parental undulating membranes dedifferentiate into undulating membranes anlage (UM-anlage) for the proter and the UM-anlage for the opisthe develops on the right of the oral primordium of the opisthe. In the proter, some membranelles (or part of some membranelles) at proximal end of the parental adoral zone of membranelles (AZM) begin to dedifferentiate (Figs 2C, E, 4F). Subsequently, the FVT-anlagen grow by increasing the number of basal bodies that become organized into many oblique streaks posteriad. The anterior end of the newly 

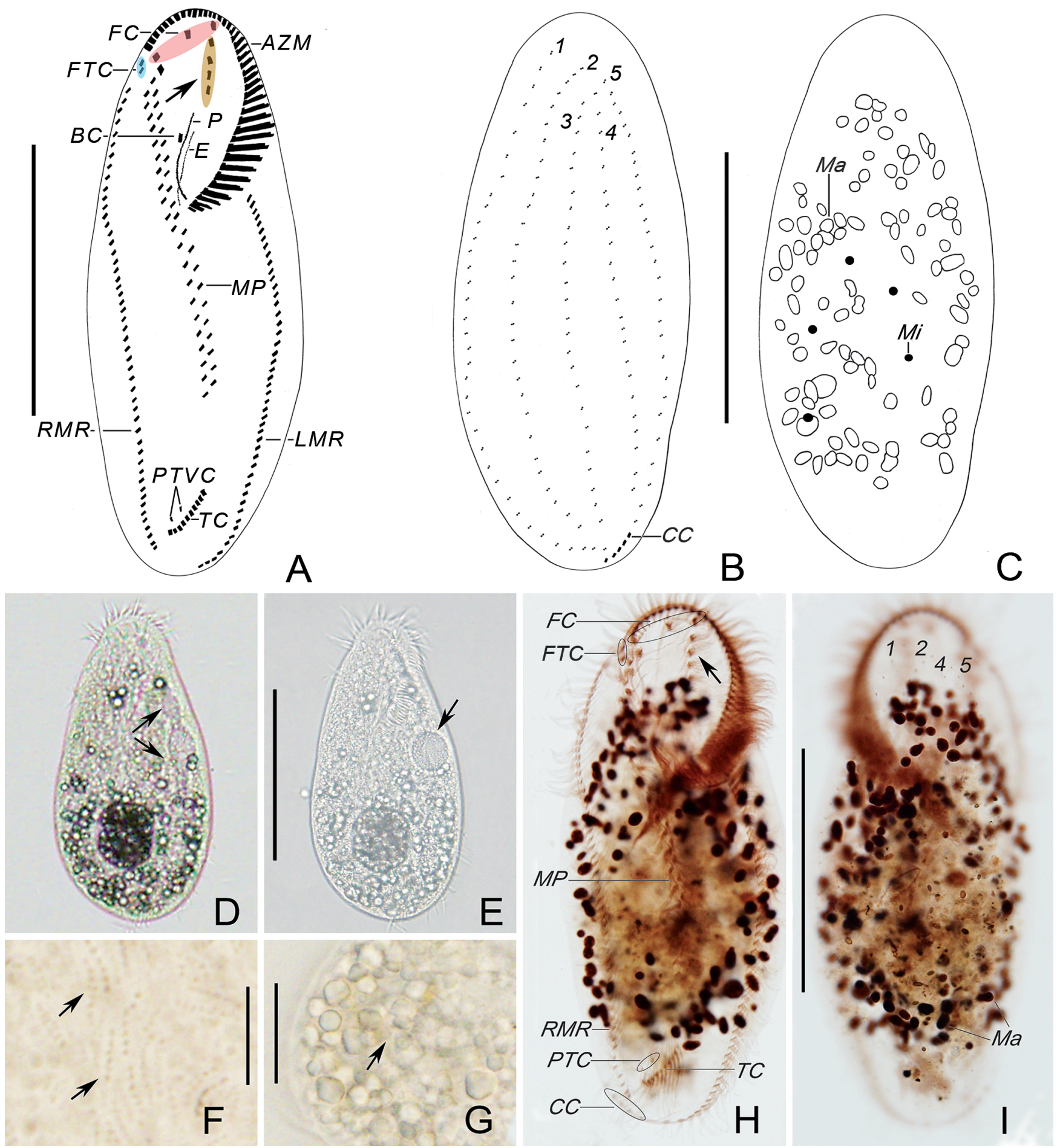

Fig. 1. A-I Illustrations of Extraholosticha sylvatica after protargol staining (A-C) and photomicrographs from life (D-G) and after protargol staining (H, I). (A-C) Ventral (A) and dorsal (B, C) view to show the general infraciliature (A, B) and the nuclear apparatus (C). Arrow in A shows the frontoventral cirri behind the leftmost frontal cirrus. (D, E) Ventral views of slightly squeezed specimens, arrows show two collecting canals (D) and the contractile vacuole (E). (F) Dorsal view, arrows point to the cortical granules. (G) Posterior portion of body, to show crystals (arrow) and lipid granules. (H) Ventral view of a representative individual, with an arrow showing the frontoventral cirri behind the leftmost frontal cirrus. (I) Dorsal view, to demonstrate dorsal kineties. AZM, adoral zone of membranelles; $\mathrm{BC}$, buccal cirrus; CC, caudal cirri; E, endoral; FC, frontal cirri; FTC, frontoterminal cirri; LMR, left marginal row; Ma, macronuclear nodules; Mi, micronuclei; MP, midventral pairs; P, paroral; PTVC, pretransverse cirri; RMR, right marginal row; TC, transverse cirri; 1-5, dorsal kineties. Scale bars $=75 \mu \mathrm{m}(\mathrm{A}-\mathrm{E}, \mathrm{H}, \mathrm{I}) ; 6 \mu \mathrm{m}(\mathrm{F}) ; 20 \mu \mathrm{m}(\mathrm{G})$. 

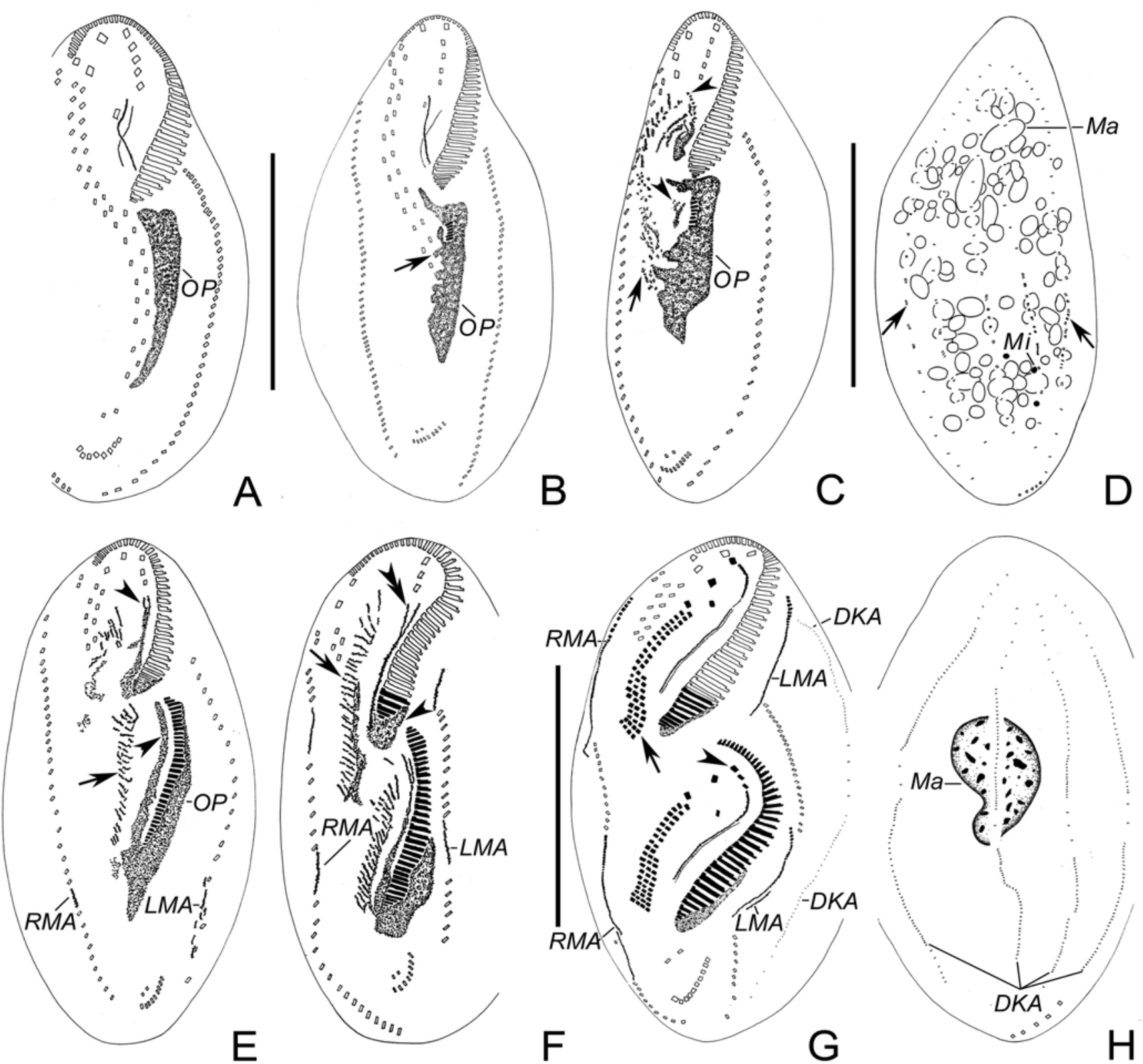

Fig. 2. A-H Morphogenesis in Extraholosticha sylvatica, after protargol staining. (A, B) Ventral views of an early divider, to show the newly formed oral primordium. Arrow shows that midventral pairs take part in the formation of oral primordium. (C, D) Ventral (C) and dorsal (D) view of an early divider. Arrow in (C) shows frontoventral-transverse cirral anlagen, arrowheads show the undulating membranes anlagen in the proter and the opisthe, while arrows in (D) note that the dorsal kineties anlagen are formed in old structure. (E) Ventral view of an early divider. Arrow shows the frontoventral-transverse cirral anlagen and arrowheads mark the undulating membranes anlagen in the proter and the opisthe. (F) Ventral view of an early divider. Note that the frontoventral-transverse cirral anlagen are developing (arrow), the posterior part of the old adoral zone of membranelles is renewed (arrowhead), the vertical split of the undulating membranes anlage (double-arrowhead) in the proter. $(\mathbf{G}, \mathbf{H})$ Ventral $(\mathrm{G})$ and dorsal $(\mathrm{H})$ view of a middle divider, arrow depicts newly formed frontoventral transverse cirri and arrowheads mark the leftmost frontal cirrus and the frontoventral cirri separated from the undulating membranes anlagen in both proter and opisthe. DKA, dorsal kineties anlagen; LMA, left marginal anlagen; Ma, macronuclear nodules; Mi, micronuclei; OP, oral primordium; RMA, right marginal anlagen. Scale bars $=75 \mu \mathrm{m}(\mathrm{A}-\mathrm{H})$. 

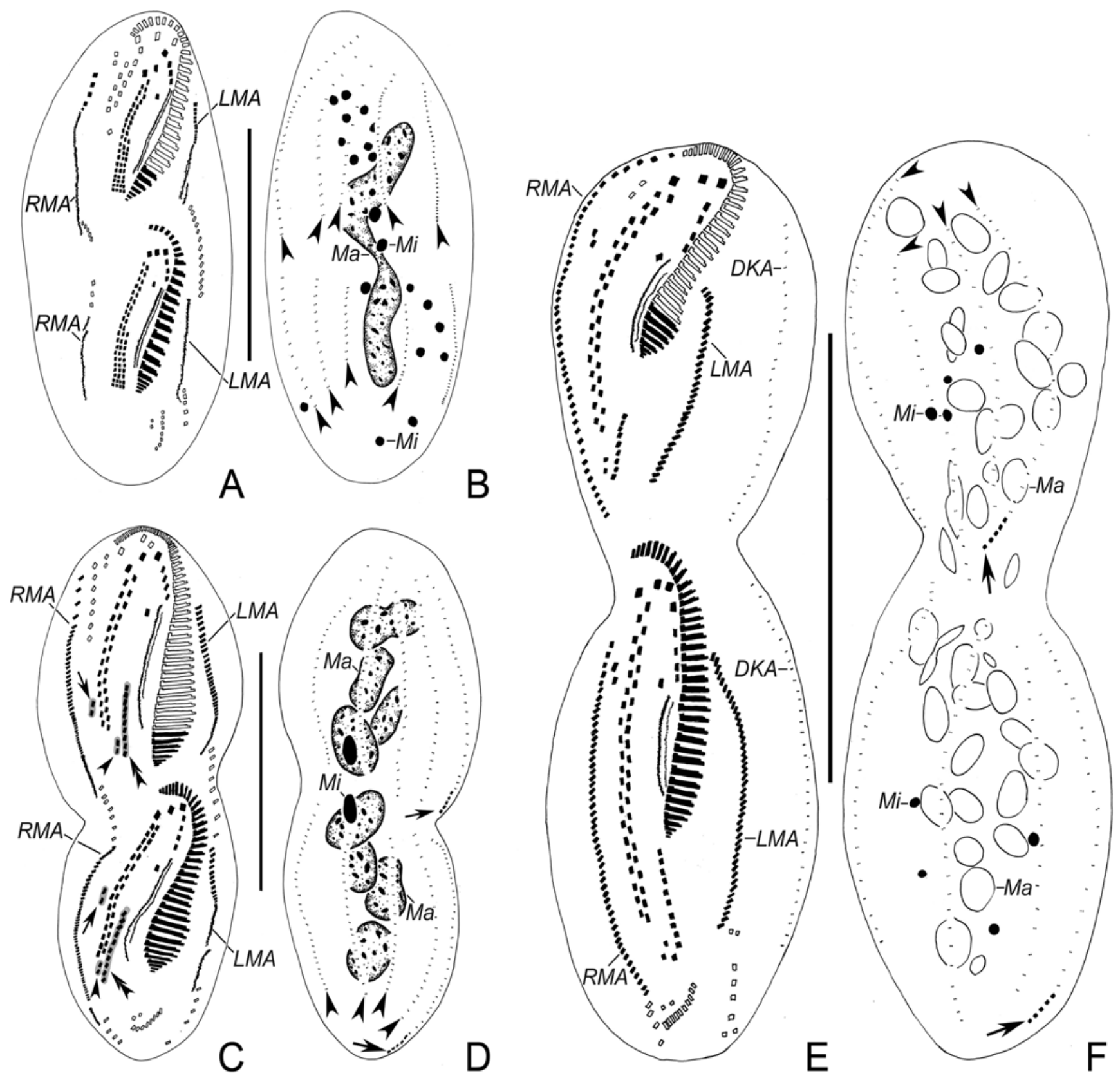

Fig. 3. A-F Morphogenesis of Extraholosticha sylvatica after protargol staining. (A, B) Ventral (A) and dorsal (B) view of a late divider. Arrowheads mark the dorsal kineties anlagen. (C, D) Ventral and dorsal view of a late divider. Note that two frontoterminal cirri (arrows in C), the pretransverse cirri (arrowheads in C), transverse cirri (double-arrowheads) and dorsal kineties anlagen (arrowheads in D) are formed in both the proter and the opisthe, as well as caudal cirri derived from the posterior end of dorsal kinety anlage 5 in both daughter cells (arrows in D). (E, F) Ventral (E) and dorsal (F) view of the same late specimen, to demonstrate that almost all the cirri have arrived their final place. Arrows denote the caudal cirri formed from dorsal kinety anlage 5 and arrowheads mark the dorsal kineties anlagen. DKA, dorsal kineties anlagen; LMA, left marginal anlagen; Ma, macronuclear nodules; Mi, micronuclei; RMA, right marginal anlagen. Scale bars $=75$ $\mu \mathrm{m}(\mathrm{A}-\mathrm{F})$. 

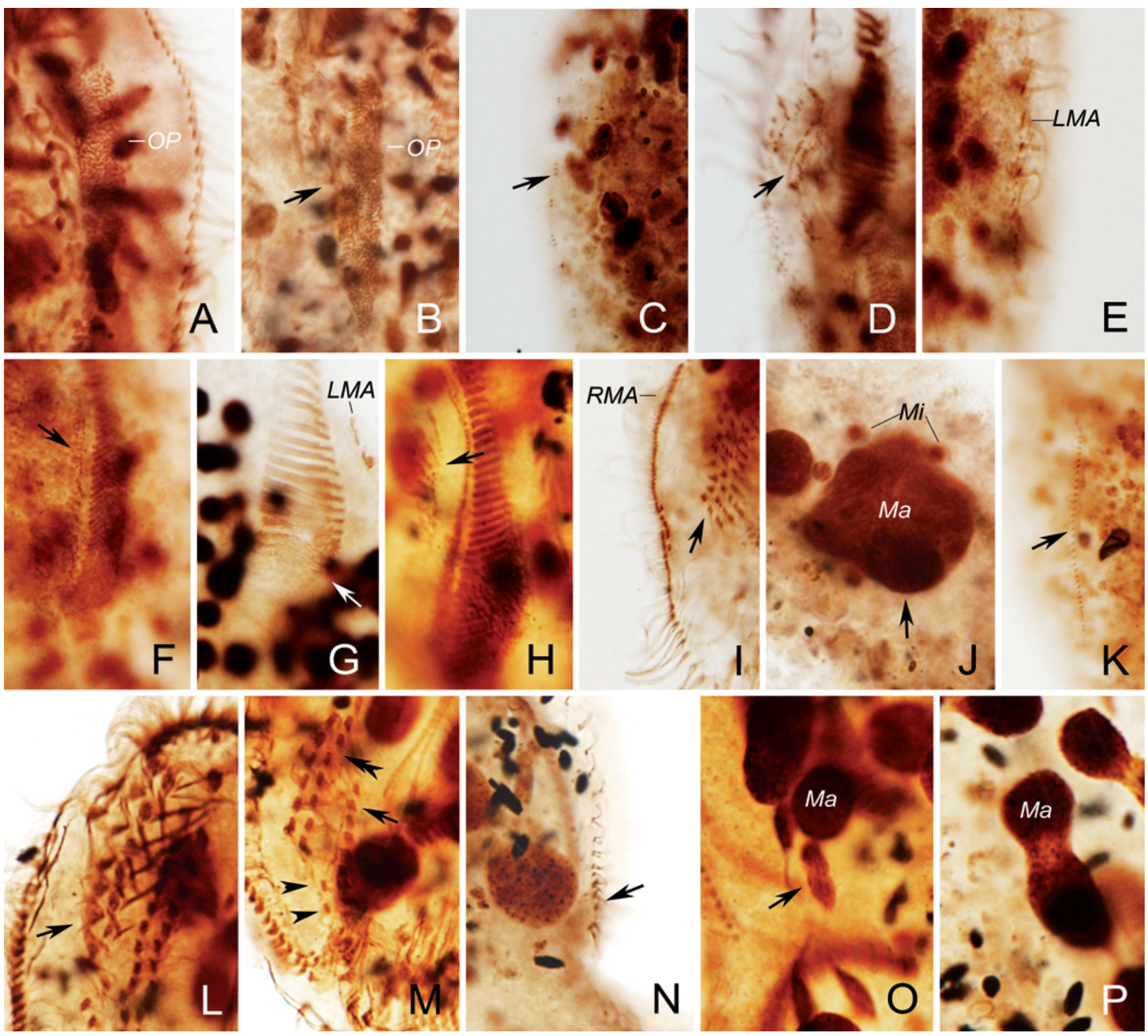

Fig. 4. A-P Photomicrographs of Extraholosticha sylvatica, during morphogenesis after protargol staining. (A, B) Ventral views of oral primordium of the opisthe. Arrow indicates the parental midventral cirri. (C) Dorsal view of an early divider, arrow shows dorsal kinety anlage. (D, H) Ventral views of early dividers, arrows show the development of the frontoventral-transverse cirral anlagen. (E) Ventral view of an early divider, to show the left marginal anlagen. (F) Ventral view of an early divider, arrow indicates the undulating membranes anlage. (G) Ventral view, arrow demonstrates that old adoral zone of membranelles was renewed in the rear part. (I, J) Ventral (I) and dorsal (J) views of a middle divider, to show the frontoventral-transverse cirral anlagen (arrow in I) and the fusing macronuclear nodule (arrow in J). (K) Ventral view of a late divider, arrow showing the dorsal kinety anlage. (L, M) Ventral views of a late divider, to show the old midventral pairs (arrow in L), as well as newly formed transverse cirri (arrow in M), pretransverse cirri (arrowheads), and midventral pairs (doublearrowhead). (N) Dorsal view, to show the caudal cirri (arrow). (O, P) Dorsal views, showing the micronuclei (arrow) and macronuclear nodule (P). LMA, left marginal anlagen; Ma, macronuclear nodules; Mi, micronuclei; OP, oral primordium; RMA, right marginal anlagen. 
built adoral zone of membranelles bends to the right and the parental AZM is renewed at its posterior end (Figs 2F, 4G, H).

By the next stage, the differentiation of membranelles is almost completed, forming the new structures for the opisthe. The FVT-anlagen continue to differentiate and each anlage develops into several cirri. In each daughter cell, four to six cirri (deduced from morphological data) develop from anterior end of the UM-anlage and later become the leftmost frontal cirrus and frontoventral cirri. Meanwhile, the undulating membranes anlage splits longitudinally to form two streaks from which the endoral and paroral derive (Fig. 2G).

Subsequently, cirri segregate from anterior to posterior in the following manner: anlage II provides the second frontal cirrus and buccal cirrus, anlage III produces rightmost frontal cirrus and cirrus III/2, anlagen IV to $n-1$ (' $n$ ' represents the last FVT-anlage) each provides one midventral cirral pair. Transverse cirri derive from anlage $n-5$ to $n-10$ (deduced from morphological data) to anlage n; two pretransverse cirri originate from anlagen $\mathrm{n}-1$ and $\mathrm{n}$; and two frontoterminal cirri develop from the last anlage (FVT-anlage n) (Figs 3A, C, 4I, L). Finally, the divider elongates and the new ciliary structures move further apart as they migrate towards their final positions (Figs 3E, 4M).

\section{Development of marginal rows and dorsal kine- ties}

As is usual for most hypotrichs, the formation of the marginal rows and dorsal kineties proceeds intrakinetally. The anlagen of the marginal rows are formed by the dedifferentiation of some cirri within each parental marginal row (Figs 2E, F, 4E, G). Then, these anlagen stretch longitudinally and gradually replace the parental structures completely (Figs 2F, G, 3A, C, E, 4 I). The dorsal kineties anlagen are also formed within the old rows in both dividers, and the proliferation of basal bodies elongate and supplant the parental structures. Three to six caudal cirri are formed at the end of the fifth dorsal kinety (Figs 2D, H, 3B, D, F, 4C, K, N).

\section{Nuclear apparatus}

The macronuclear nodules fuse to form a single mass during the middle divisional stage and then divide to form numerous nodules for each filial cell. Micronuclei were observed to divide mitotically (Figs 2D, H, 3B, D, F, 4J, O, P).

\section{DISCUSSION}

\section{Identification of the Chinese population of Extraho- losticha sylvatica}

Extraholosticha sylvatica was originally discovered by Foissner (1982) and redescribed by Borror and Wicklow (1983), Berger and Foissner (1989), Shin and Kim (1993) and Kumar et al. (2010). The Chinese population of Extraholosticha sylvatica is identical to the previous descriptions of this species, so its identity is not in doubt.

\section{Morphogenesis}

Kumar et al. (2010) described the morphogenesis of Silent Valley population of Extraholosticha sylvatica, which a partial description was made based on three dividers, most ontogenetic events of this species were unknown. In this work, we give detailed information on the formation of oral primordium, macronuclear nodules, frontoventral transverse cirri, marginal cirral row and the dorsal kineties.

Combine the information from both the Indian and Chinese populations, the most remarkable characteristic events during morphogenesis in Extraholosticha sylvatica can be summarized as follows: (a) undulating membranes anlage contributes more than one cirrus. Among urostylids, this also happens in several species/ genera, e.g., Epiclintes auricularis, Trichototaxis songi and Uroleptopsis citrine, however, the number of cirri generated from undulating membranes anlage is four to six in the present species, whereas it is two in the latter three species (Berger 2004; Hu et al. 2009; Shao et al. 2014a, b); (b) all the caudal cirri are formed at posterior end of the $5^{\text {th }}$ dorsal kinety anlage in the present species. Caudal cirri are present in minority of urostylids, e.g., Australothrix, Caudikeronopsis, Eschaneustyla, Holostichides and Paragastrostyla, and in these genera, caudal cirri are mostly generated from all the dorsal kineties anlagen, except in Caudikeronopsis, caudal cirri are formed from two of the dorsal kineties anlagen (Berger 2006; Deng et al. 2018; Li et al. 2016; Lyu et al. 2015, 2018a, b; Song 1990; Zhu et al. 2019). Whereas, in the present species, the caudal cirri develop from only one anlage, that is similar to the formative pattern in euplotids and some oxytrichids. However, according to Lyu et al. (2018c), Extraholosticha sylvatica had a close relationship with Anteholosticha monilata and did not cluster with any of the above species/genera. Therefore, we deduce that these two shared apomorphies evolved convergently. 
Acknowledgments. This work was supported by the Natural Science Foundation of China (Project number: 31872190).

\section{REFERENCES}

Berger H. (1999) Monograph of the Oxytrichidae (Ciliophora, Hypotrichia). Monogr. Biol. 78: 1-1080

Berger H. (2003) Redefinition of Holosticha Wrzesniowski, 1877 (Ciliophora, Hypotricha). Eur. J. Protistol. 39: 373-379

Berger H. (2004) Uroleptopsis Kahl, 1932 (Ciliophora: Hypotricha): morphology and cell division of type species, redefinition, and phylogenetic relationships. Acta Protozool. 43: 99-121

Berger H. (2006) Monograph of the Urostyloidea (Ciliophora, Hypotricha). Monogr. Biol. 85: 1-1303

Berger H. (2008) Monograph of the Amphisiellidae and Trachelostylidae (Ciliophora, Hypotricha). Monogr. Biol. 88: 1-737

Berger H. (2011) Monograph of the Gonostomatidae and Kahliellidae (Ciliophora, Hypotricha). Monogr. Biol. 90: 1-741

Berger H., Foissner W. (1989) Morphology and biometry of some soil hypotrichs (Protozoa, Ciliophora) from Europe and Japan. Bull. Br. Mus. Nat. Hist. Zool. 55: 19-46

Borror A. C., Wicklow B. J. (1983) The suborder Urostylina Jankowski (Ciliophora, Hypotrichida): morphology, systematics and identification of species. Acta Protozool. 22: 97-126

Chen L., Wu W., El-Serehy H. A., Hu X., Clamp J. C. (2018) Morphology, morphogenesis, and phylogeny of an Anteholosticha intermedia (Ciliophora, Urostylida) population from the United States. Eur. J. Protistol. 65: 1-15

Deng Y., Lu X., Li J., Ba S., Paiva T. P. (2018) Morphology of two Eschaneustyla species (Ciliophora, Urostylida), with notes on morphogenesis of Eschaneustyla lugeri. Acta Protozool. 57: 69-78

Foissner W. (1982) Ökologie und Taxonomie der Hypotrichida (Protozoa: Ciliophora) einiger österreichischer Böden. Arch. Protistenk. 126: 19-143

Foissner W. (2014) An update of 'basic light and scanning electron microscopic methods for taxonomic studies of ciliated protozoa'. Int. J. Syst. Evol. Microbiol. 64: 271-292

Foissner W. (2016) Terrestrial and semiterrestrial ciliates (Protozoa, Ciliophora) from Venezuela and Galápagos. Denisia 35: 1-912

Hu X., Fan X., Lin X., Gong J., Song W. (2009) The morphology and morphogenesis of a marine ciliate, Epiclintes auricularis rarisetus nov. spec. (Ciliophora, Epiclintidae), from the Yellow Sea. Eur. J. Protistol. 45: 281-291

Jung J., Berger H. (2019) Monographic treatment of Paraholosticha muscicola (Ciliophora, Keronopsidae), including morphological and molecular biological characterization of a brackish water population from Korea. Eur. J. Protistol. 68: 48-67

Jung J. H., Cho J., Jang Y. H., \& Gil D. Y. (2018) Morphology and molecular phylogeny of Holostichides terrae nov. spec. (Ciliophora: Spirotrichea) with discussion on the possible nonmonophyly of Holostichides. Eur. J. Protistol, 62: 69-78

Kaur H., Negi S. R. K., Kamra K. (2019) Morphological and molecular characterization of Neogastrostyla aqua nov. gen., nov. spec. (Ciliophora, Hypotrichia) from River Yamuna, Delhi; comparison with Gastrostyla-like genera. Eur. J. Protistol. 68: 68-79

Kumar S., Kamar K., Sapra G. (2010) Ciliates of the Silent Valley National Park, India: Urostyloid Hypotrichs of the region with a note on the habitat. Acta Protozool. 49: 339-364

Kumar S., Bharti D., Kabir A. S., Hong J., Shin M. (2018) Rubrioxytricha guamensis nov. spec. (Ciliophora, Spirotricha), a novel hypotrich ciliate from Guam (United States), Micronesia. J. Eukaryot. Microbiol. 65: 392-399

Li J., Chen X., Xu K. (2016) Morphology and small subunit DNA phylogeny of two new marine urostylid ciliates, Caudiholosticha marina sp. nov. and Nothoholosticha flava sp. nov. (Ciliophora, Hypotrichia). J. Eukaryot. Microbiol. 63: 460-470

Li F., Lyu Z., Li Y., Fan X., Al-Farraj S. A., Shao C., Berger H. (2017) Morphology, morphogenesis, and molecular phylogeny of Uroleptus (Caudiholosticha) stueberi (Foissner, 1987) comb. nov. (Ciliophora, Hypotricha), and reclassification of the remaining Caudiholosticha species. Eur. J. Protistol. 59: 82-98

Luo X., Yan Y., Shao C., Al-Farraj S. A., Bourland W. A., Song W. (2018) Morphological, ontogenetic and molecular data support strongylidiids as being closely related to Dorsomarginalia (Protozoa, Ciliophora) and reactivation of the family Strongylidiidae Fauré-Fremiet, 1961. Zool. J. Linn. Soc. 184: 237-254

Luo X., Huang J. A., Li L., Song W., Bourland W. A. (2019) Phylogeny of the ciliate family Psilotrichidae (Protista, Ciliophora), a curious and poorly-known taxon, with notes on two algaebearing psilotrichids from Guam, USA. BMC Evol. Biol. 19: 125

Lyu Z., Shao C., Yi Z., Warren A. (2015) A molecular phylogenetic investigation of Bakuella, Anteholosticha, and Caudiholosticha (Protista, Ciliophora, Hypotrichia) based on three-gene sequences. J. Eukaryot. Microbiol. 62: 391-399

Lyu Z., Li J., Qi S., Yu Y., Shao C. (2018a) Morphology and morphogenesis of a new soil urostylid ciliate, Australothrix xianiensis nov. spec. (Ciliophora, Hypotrichia). Eur. J. Protistol. 64: $72-81$

Lyu Z., Li J., Zhu E., Shao C. (2018b) Morphology and morphogenesis of a new soil urostylid ciliate, with the establishment of a new genus Caudiurostyla gen. nov. (Ciliophora, Hypotrichia). Eur. J. Protistol. 66: 166-176

Lyu Z., Wang J., Huang J., Warren A., Shao C. (2018c) Multigenebased phylogeny of Urostylida (Ciliophora, Hypotrichia), with establishment of a novel family. Zool. Scr. 47: 243-254

Méndez-Sánchez D., Mayén-Estrada R., Luo X., Hu X. (2018) A new subspecies of Oxytricha granulifera (Hypotrichia: Oxytrichidae) from Mexico, with notes on its morphogenesis and phylogenetic position. J. Eukaryot. Microbiol. 65: 357-371

Moon J. H., Kim J. H., Quintela-Alonso P., Jung J. H. (2019). Morphology, morphogenesis, and molecular phylogeny of Neobakuella aenigmatica n. sp. (Ciliophora, Spirotrichea, Bakuellidae). J. Eukaryot. Microbiology. 67: 54-65

Pan X., Bourland W., Song W. (2013) Protargol synthesis: an inhouse protocol. J. Eukaryot. Microbiol. 60: 609-614

Shao C., Li L., Zhang Q., Song W., Berger H. (2014a) Molecular phylogeny and ontogeny of a new ciliate genus, Paracladotricha salina n. g., n. sp. (Ciliophora, Hypotrichia). J. Eukaryot. Microbiol. 61: 371-380

Shao C., Lv Z., Jin L., Warren A. (2014b) Morphogenesis of a unique pseudourostylid ciliate, Trichototaxis songi (Ciliophora, Urostylida). Eur. J. Protistol. 50: 68-77

Shao C., Hu C., Fan Y., Warren A., Lin X. (2019). Morphology, morphogenesis and molecular phylogeny of a freshwater ciliate, Monomicrocaryon euglenivorum euglenivorum (Ciliophora, Oxytrichidae). Eur. J. Protistol. 68: 25-36

Sheng Y., He M., Zhao F., Shao C., Miao M. (2018) Phylogenetic relationship analyses of complicated class Spirotrichea based on transcriptomes from three diverse microbial eukaryotes: Uroleptopsis citrina, Euplotes vannus and Protocruzia tuzeti. Mol. Phylogenet. Evol. 129: 338-345 
Shin M. K., Kim W. (1993) Redescription of two holostichid species of genus Holosticha Wrzesniowski 1877 (Ciliophora, Hypotrichida, Holostichidae) from Seoul, Korea. Korean J. Syst. Zool. 1: 251-259

Song W. (1990) Morphologie und Morphogenese des bodenciliaten Periholosticha wilberti nov. spec. (Ciliophora, Hypotrichida). Arch. Protistenk. 138: 221-231

Song W., Shao C. (2017). Ontogenetic patterns of hypotrichs ciliates. Science Press. (in Chinese) 12: 1-497

Wilbert N. (1975) Eine verbesserte technik der Protargolimprägnation für ciliaten. Mikrokosmos. 64: 171-179

Zhang T., Qi H., Zhang T., Sheng Y., Warren A., Shao C. (2019) Morphology, morphogenesis and molecular phylogeny of a new brackish water subspecies, Neourostylopsis flava paraflava nov. subsp. (Ciliophora, Hypotrichia, Urostylidae), with redefinition of the genus Neourostylopsis. Eur. J. Protistol. 66: 48-62

Zhu E., Ba S., Lyu Z., Li J., Shao C. (2019) Morphogenesis and molecular phylogeny of the soil ciliate Holostichides chardezi (Ciliophora, Hypotrichia, Bakuellidae), with redefinition of $\mathrm{Ho}$ lostichides Foissner, 1987 and establishment of a new genus Anteholostichides. J. Eukaryot. Microbiol. 66: 730-739

Received on $8^{\text {th }}$ October, 2019; revised on $25^{\text {th }}$ January, 2020; accepted on $10^{\text {th }}$ February, 2020 